\title{
A Light and Electron Microscopic Study on Pulpal Nerve Fibers in the Lower Incisor of the Mouse
}

\author{
Hiroshi Ishizuka and Akio HiURA \\ Department of Oral Anatomy, Tokushima University School of Dentistry, Tokushima, Japan \\ Received September 30, 1991
}

\begin{abstract}
Summary. Light and electron microscopic studies were made on pulpal nerve fibers in mouse lower incisors, typical continuously growing teeth. Serial sections, from the apex of the odontogenic sheath to the incisal edge of the apical foramen, were examined by light microscopy to identify myelinated fibers passing through the apical foramen. The fine structure of the pulpal nerves was examined by electron microscopy at three sites: 1) the level at the incisal edge of the apical foramen; 2) a level $5 \mathrm{~mm}$ incisal from the apex of the odontogenic sheath; and 3) the level where the incisor comes out of the alveolar bone.

No myelinated fibers were found passing through the apical foramen; they were also lacking at the three levels of the pulp. At level 2, unmyelinated axons were seen in close contact with smooth muscle fibers of arterioles. At level 3, nerve fibers were difficult to distinguish from processes of fibroblasts and odontoblasts. Degenerating axons were present in Schwann cells, and fine unmyelinated axons running through the odontoblast cell layer were seen.

Various types of unmyelinated axons were observed in the apical region (level 1). These axons were classified into 6 types on the basis of their fine structures: Type I, bundles of unmyelinated axons completely or partly ensheathed by Schwann cell cytoplasm (mature type); Type II, bundles of unmyelinated axons in a space formed by a Schwann cell membrane (regenerating type); Type III, bundles of unmyelinated axons ensheathed not by a Schwann cell, but merely by a basal lamina (regenerating type); Type IV, single axons in direct contact with the basal lamina (regenerating or terminal type); Type $\mathrm{V}$, naked, electron-dense axons with many vesicles and mitochondria (growth cone-like type); and Type VI, electron opaque axons, due to loss of axonal organellae (degenerating type). The significance of these structures is discussed in relation to the continuous growth of the rodent incisor.
\end{abstract}

Rodent incisors are characterized by their continuous growth. The pulpal nerves in rodent incisors also grow continuously (HATTYASY, 1956), and previous investingators have considered that the nerves might be immature in nature (ZAJICEK, 1976; BISHOP, 1981; Sugimoto et al., 1981; KuBOtA et al., 1985).

There have been many ultrastructural studies on the pulpal nerve fibers in the rat incisor (NAKAMURA et al., 1979; Bishop, 1981; SUGIMOTO et al., 1981; KATAYAMA, 1982; KuBOTA et al., 1985). Reports have shown that its pulp includes many unmyelinated and a few myelinated fibers, and that nerve fibers are associated with, or lie near blood vessels. BISHOP (1981), Sugimoto et al. (1981) and KuBotA et al. (1985) distinguished three types of unmyelinated fibers: unmyelinated axons entirely or partly ensheathed by Schwann cell, clusters of bare unmyelinated axons surrounded by basal lamina, and bare axons not associated with Schwann cells. Many experimental studies have been carried out to characterize the nature of incisor pulpal nerves in rats (BYERS, 1984). In the mouse, however, little information has been available concerning the nerve fibers in the pulp of incisors (for review, BYERS, 1984). The present study examined their fine structure to provide new findings for understanding the nature of the nerves in the continuous growing teeth.

\section{MATERIALS AND METHODS}

Four ICR mice, 6 months in age, were used in this study. Under anesthesia with Nembutal, the animals were perfused through the left ventricle first with saline and then with a fixative containing $2.5 \%$ glutaraldehyde and 5\% paraformaldehyde in $0.1 \mathrm{M}$ phosphate buffer ( $\mathrm{pH} 7.4$ ) containing 2.5\% sucrose. Then the mandible with incisors was excised, and attached muscles were removed. The specimens were refixed in the same fixative for $2-4 \mathrm{~h}$ at $4^{\circ} \mathrm{C}$. After fixation, the specimens were decalcified at $4^{\circ} \mathrm{C}$ for 10 
days in $0.08 \mathrm{M}$ EDTA in cacodylate buffer under constant agitation with daily changes of the solution. The decalcified specimens were postosmicated for $2 \mathrm{~h}$, dehydrated and embedded in Epon 812 resin.

In order to examine the occurrence of myelinated fibers passing through the apical foramen, serial cross-sections were made from the apex of the odontogenic sheath (MICHAELI and GREULICH, 1972) to the incisal edge of the apical foramen, and stained with toluidine blue; 4500 semi-thin sections of these regions were observed by light microscopy.

Ultrathin sections were made at three levels of the pulp; the apical region at the incisal edge of the apical foramen (line 1 in Fig. 1), a level $5 \mathrm{~mm}$ incisal from the apex of the odontogenic sheath (line 2 in Fig. 1), and the level where the incisor comes out of the alveolar bone (line 3 in Fig. 1). Ultrathin sections were placed on Formvar-coated single hole grids and doubly stained with uranyl acetate and lead nitrate. These sections were examined with a Hitachi H-500 electron microscope.

\section{RESULTS}

\section{Light microscopic observations}

As shown in Figures 1 and 2, the apical foramen of the mouse incisor was situated on the lingual side. No myelinated fibers passing through the apical foramen could be detected in serial semi-thin sections.

\section{Electron microscopic observations}

Unmyelinated fibers not surrounded by a perineurium were seen among or near blood vessels. No myelinated fibers were found at any sites of the incisor pulp examined.

\section{1) Unmyelinated axons at level 1}

Unmyelinated fibers, as seen in the boxed area in Figure 3 , were conspicuously variable in size and formed both larger and smaller bundles consisting of axons of different types, i.e., axons completely ensheathed by Schwann cell cytoplasm (Fig. 4), axons partly ensheathed by Schwann cell processes (Fig. $5 a)$, axons in a space surrounded by a Schwann cell, forming a common mesaxon (Fig. 5b), axons not ensheathed by Schwann cell but directly by basal lamina (bundles of bare unmyelinated axons) (Fig. 5c, d), and unmyelinated axons not ensheathed by a Schwann cell (bare axons) (Fig. 5e). In addition, bare axons with many vesicles and mitochondria were seen (Fig. $5 \mathrm{f}$ ). Also occasionally seen were degenerat-

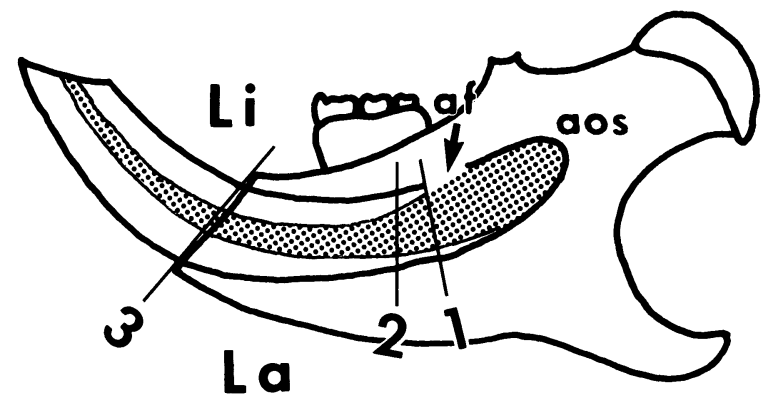

Fig. 1. Diagram of a longitudinal section of the mouse lower incisor. Lines 1, 2 and 3 indicate the levels where the pulp nerves were cross-sectioned in this study. Line 1, the apical region at the incisal edge of the apical foramen; line 2, the level $5 \mathrm{~mm}$ incisal from the apex of the odontogenic sheath; line 3 , the level of outgrowth of the incisor from the alveolus. af apical foramen, aos apex of the odontogenic sheath, $L a$ labial side, $L i$ lingual side.

ing axons showing electron opaque axoplasm due to the absence of axonal organellae (Figs. 4, 5).

\section{2) Unmyelinated axons at level 2}

Many unmyelinated axons ensheathed by Schwann cells were seen close to blood vessels (Fig. 6a). Some of these axons appeared in close contact with smooth muscle fibers of arterioles (Fig. 6b).

\section{3) Unmyelinated axons at level 3}

Here, the pulp cavity was greatly reduced in size. Unmyelinated axons were difficult to distinguish from fibroblastic or odontoblastic cell processes. Both single and bundles of unmyelinated axons, showing degeneration, were ensheathed in a Schwann cell (Fig. $7 \mathrm{a}, \mathrm{b}$ ). Occasionally, very fine naked axons were seen running into the odontoblast layer (Fig. 8).

\section{DISCUSSION}

No myelinated fibers were found at the three sites of the mouse lower incisor pulp. The features of unmyelinated fibers in the apical region are similar to those reported in the rat (BISHOP, 1981; SUGIMOTO et al., 1981; KATAYAMA, 1982; KuBOTA et al., 1985), but different in the other two sites in the pulp.

Despite careful examinations, we could not find any branches of nerve fibers passing the apical foramen from the inferior alveolar nerve. At least in the mouse, nerve fibers passing through the apical foramen are exclusively fine unmyelinated ones. In rat 


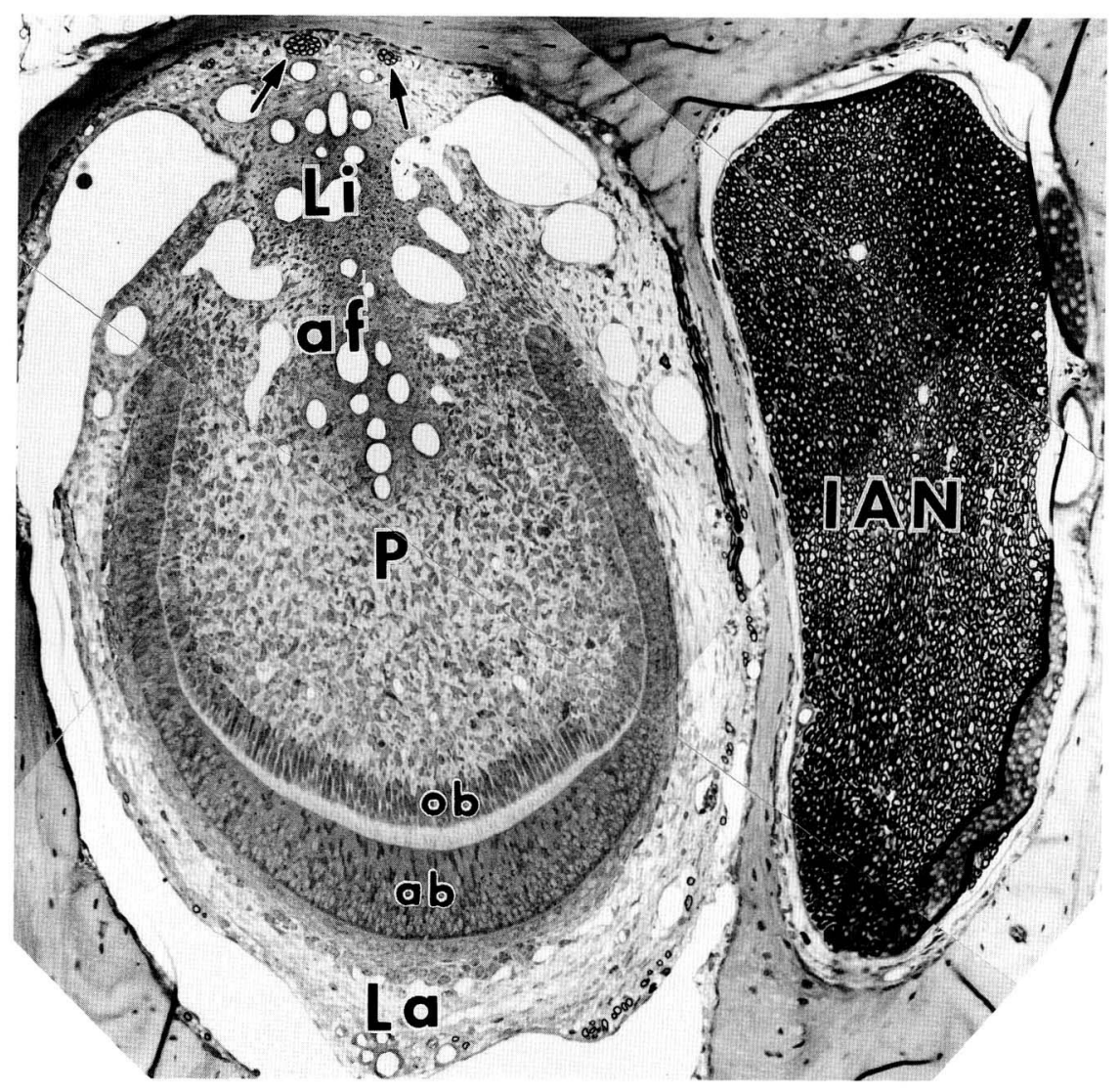

Fig. 2. Light micrograph of a cross-section of the incisor with the apical foramen still open. The bundles of myelinated fibers (arrows) do not enter the apical foramen. $a b$ Ameloblast, af apical foramen, IAN inferior alveolar nerve in the mandibular canal, $L a$ labial side, $L i$ lingual side, ob odontoblast, $P$ pulp. $\times 150$

incisors it has been reported that myelinated fibers lose their myelin sheath during passage through the apical foramen (HIURA et al., 1973; SAKAI, 1974; Sugimoto et al., 1981; Katayama, 1982; Kubota et al., 1985). The possibility that, in the mouse, myelinated fibers lose their myelin sheath outside the apical foramen must be examined in further studies.

Various types of unmyelinated fibers were recognizable in the apical region, and we classified them into six types: a bundle of axons completely or partly ensheathed in a Schwann cell (Type I), a bundle of axons in a space formed by a Schwann cell (Type II), a bundle of axons devoid of a Schwann cell sheath (bundles of bared unmyelinated axons, Type III), single axons directly surrounded by a basal lamina (bare axons, Type IV), electron-dense, naked axons containing many vesicles and mitochondria (growth cone-like axons, Type V), and electron opaque axons devoid of axonal organellae (degenerating axons, Type VI). Type I corresponds to the mature type of unmyelinated axons, and Type II to the immature type described by others (BISHOP, 1981; Sugimoto et al., 1981). Growth cones and regenerating axons are characterized by large accumulations of various vesicles, mitochondria and neurofilaments (WETTSTEIN and Sotelo, 1963; LAMPERT, 1967; TENNYSON, 1970; YAMADA et al., 1971). Type $\mathrm{V}$ axons include large numbers of vesicles and mitochondria in their electrondense axoplasm, probably due to the accumulation of filamentous materials. In this respect, Type $\mathrm{V}$ seems to correspond to the growth cone part rather than terminals, as suggested by BisHOP (1981).

Many unmyelinated axons ensheathed by a Schwann cell were observed in close contact with blood vessels in the level $5 \mathrm{~mm}$ incisal from the apex of the odontogenic sheath. This close contact of the axons with blood vessels in this area is consistent with the report by ZAJICEK (1976).

At the level where the tooth comes out of the alveolus, nerve fibers were difficult to distinguish 


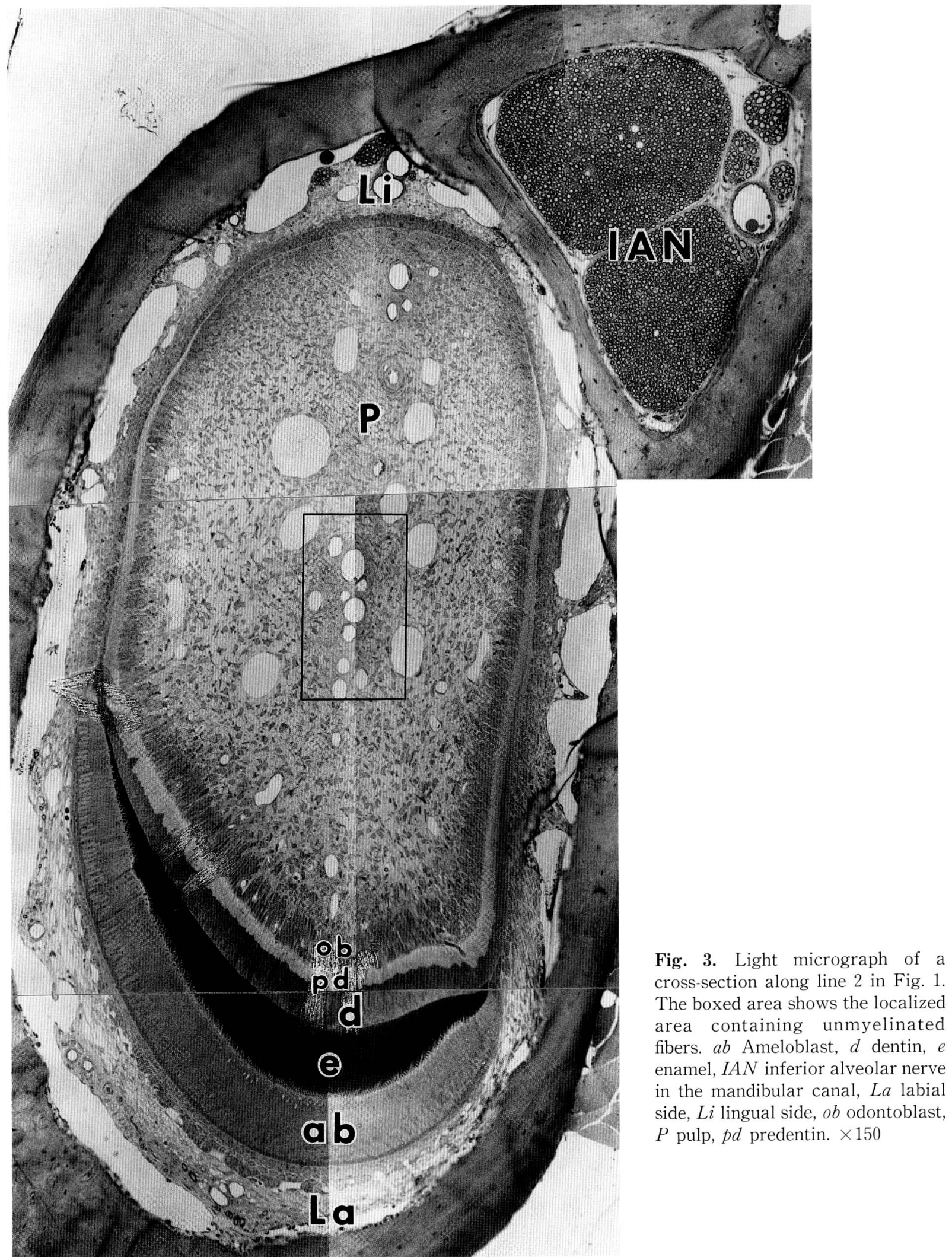


Fig. 4. Electron micrograph of unmyelinated axons ensheathed by a Schwann cell (Type I) seen in the apical region (line 1 in Fig. 1). Note that the largest axons are present in unmyelinated axons. Occasionally, axons devoid of axonal organellae (asterisks, Type VI) can be seen among the intact axons. $F b$ fibroblast, SC Schwann cell. $\times 26,600$

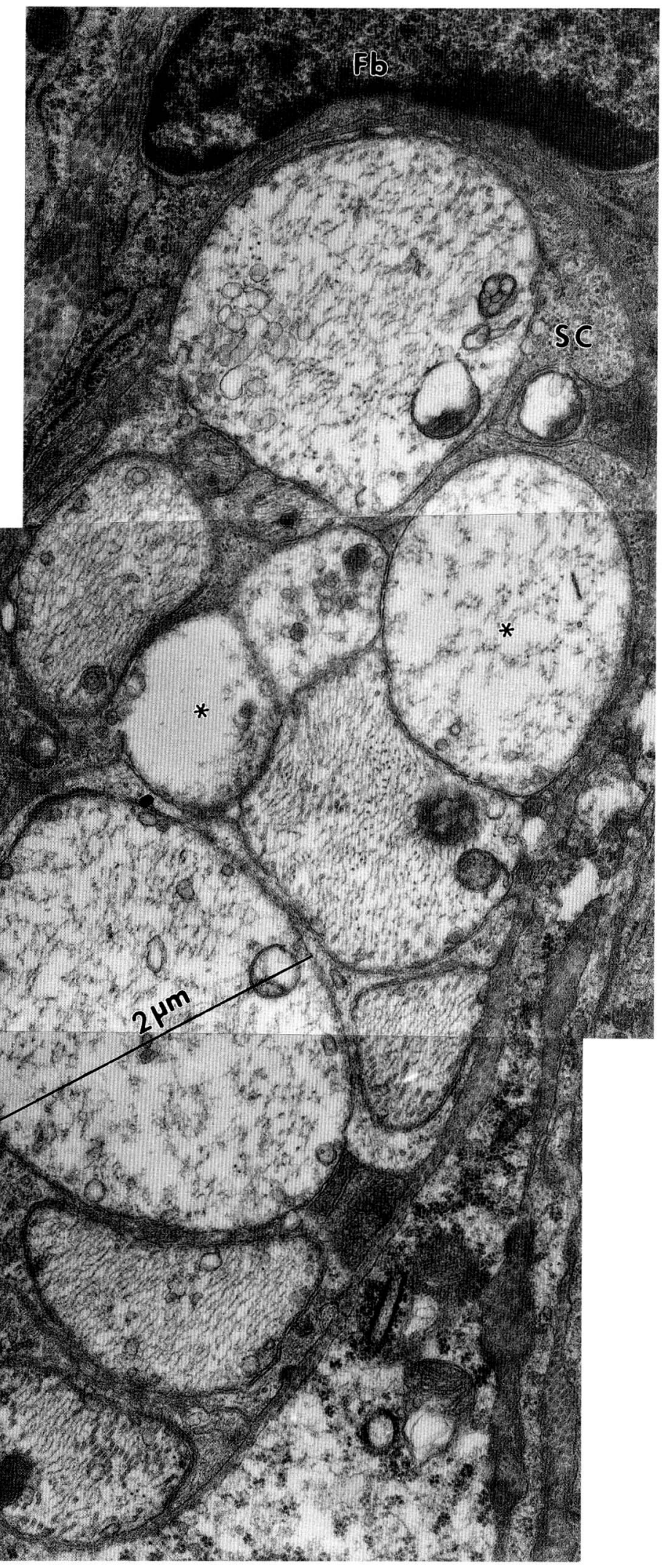



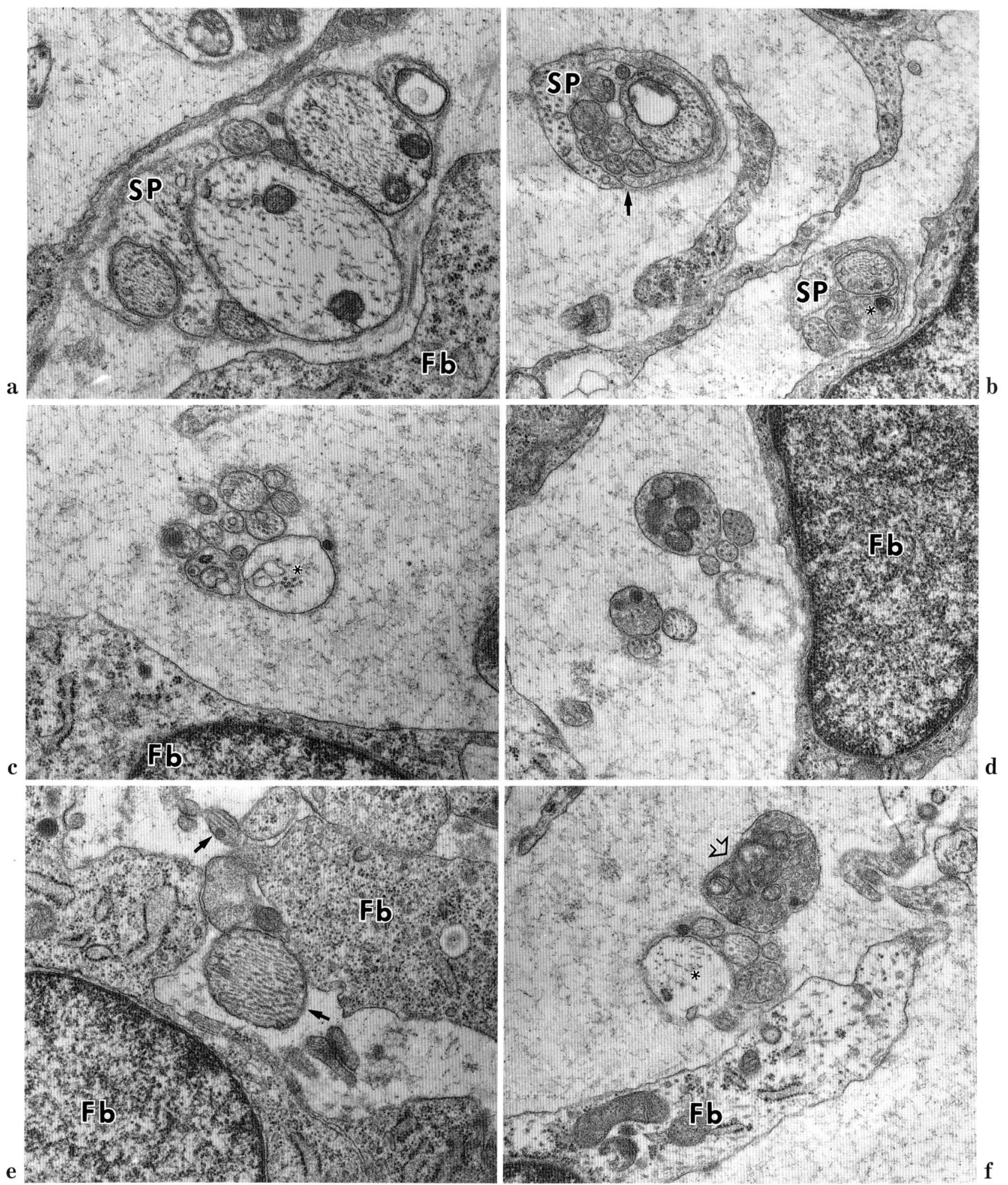

Fig. 5. Different types of unmyelinated fibers seen in the apical region. a. A bundle of unmyelinated axons partly ensheathed by a Schwann cell (Type I). b. Bundles of unmyelinated axons in a space formed by a common mesaxon (arrow, Type II). c. A bundle of unmyelinated axons not ensheathed by a Schwann cell but directly by basal lamina (Type III). d. Bundles of unmyelinated axons devoid of a Schwann cell (Type III). e. Bare axons (arrows, Type IV). f. An electron-dense bare axon (open arrow) with various vesicles and mitochondria (Type V). Asterisks show degenerating axons (Type VI). Fb fibroblast. SP Schwann cell process. $\times 21,500$ 

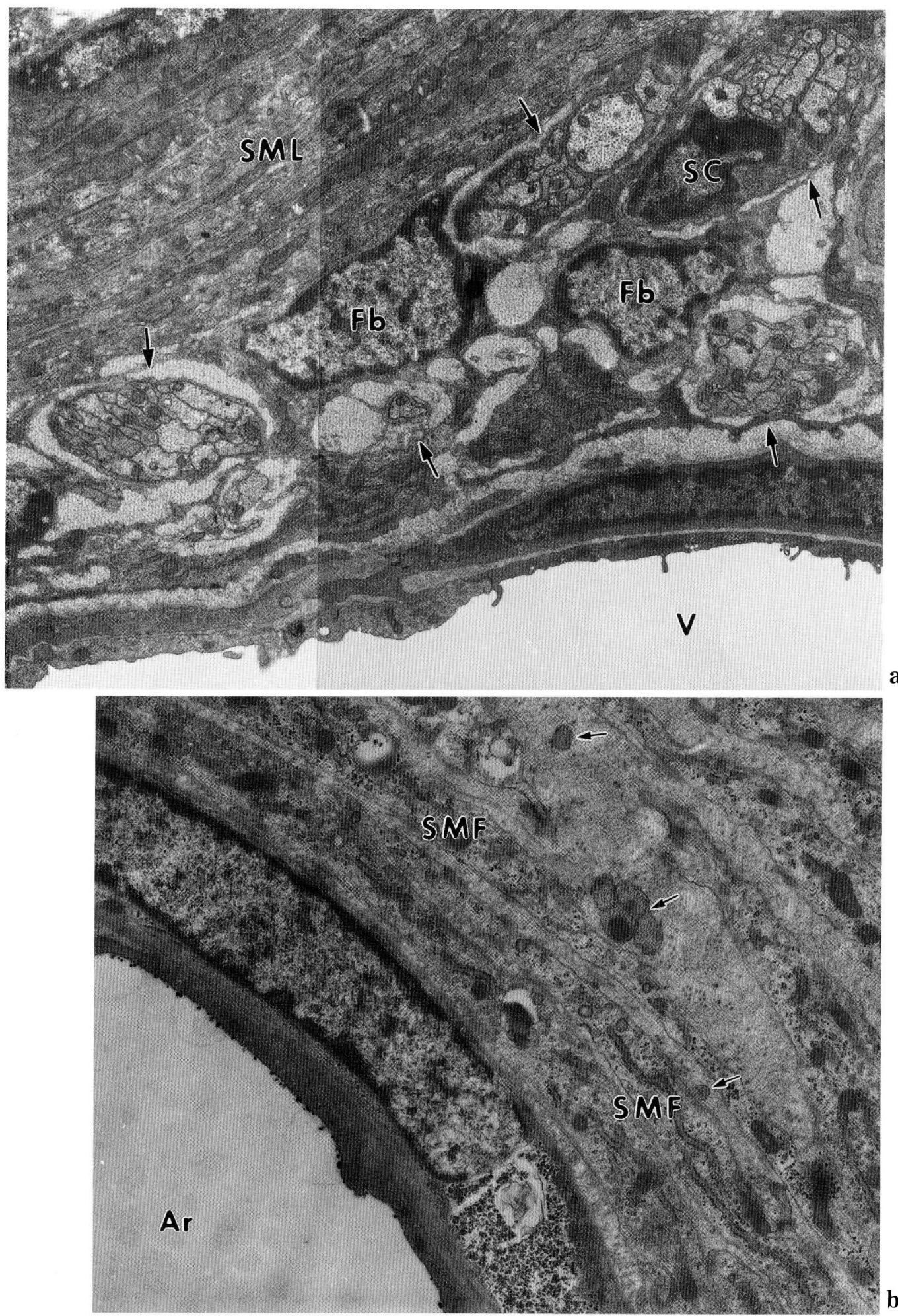

Fig. 6. Unmyelinated fibers seen in the pulp $5 \mathrm{~mm}$ incisal from the apex of the odontogenic sheath (line 2 in Fig. 1). a. Bundles of unmyelinated axons (arrows) in close contact with smooth muscle fibers of arterioles. $\times 9,800$. b. Unmyelinated axons (arrows) in close contact with muscle fibers of an arteriole. $A r$ arteriole, $F b$ fibroblast, $S c$ Schwann cell, $S M F$ smooth muscle fiber, $S M L$ smooth muscle layer outside the arteriole, $V$ vessel. $\times 12,600$ 


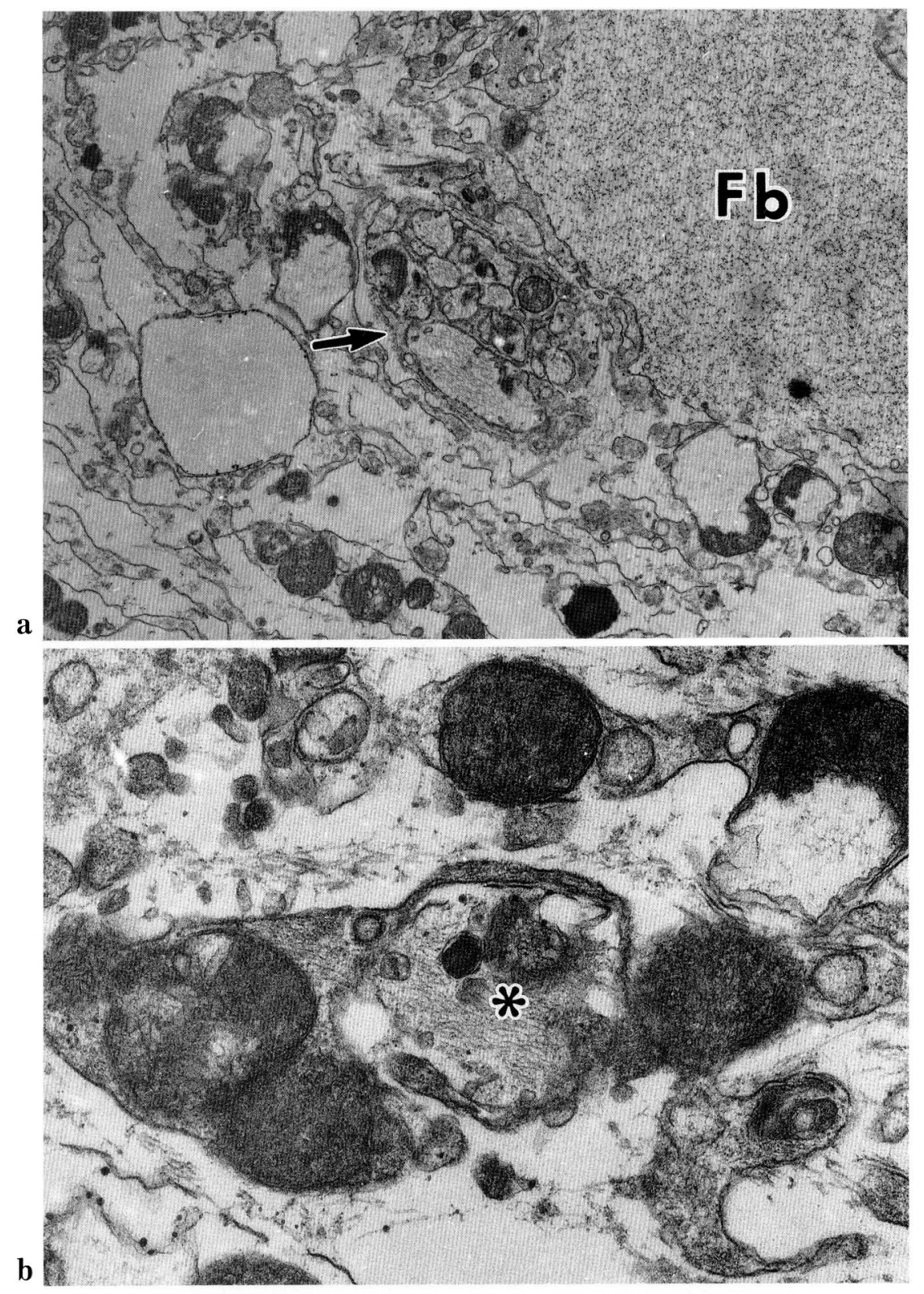

Fig. 7. Unmyelinated fibers seen in the pulp at the level of incisor eruption (line 3 in Fig. 1). a. A bundle of unmyelinated axons (arrow) in a Schwann cell, showing degeneration. $\times 11,500$. b. A degenerating unmyelinated axon (aster isk). $\mathrm{Fb}$ fibroblast. $\times 34,600$

Fig. 8. Fine naked unmyelinated axon (arrows) running between two odontoblasts $(O b)$ to the odontogenic area seen in the pulp at the level of the incisor eruption. Note the bead-like structure and neurofilaments. $N u$ nucleus. $\times 58,900$ 


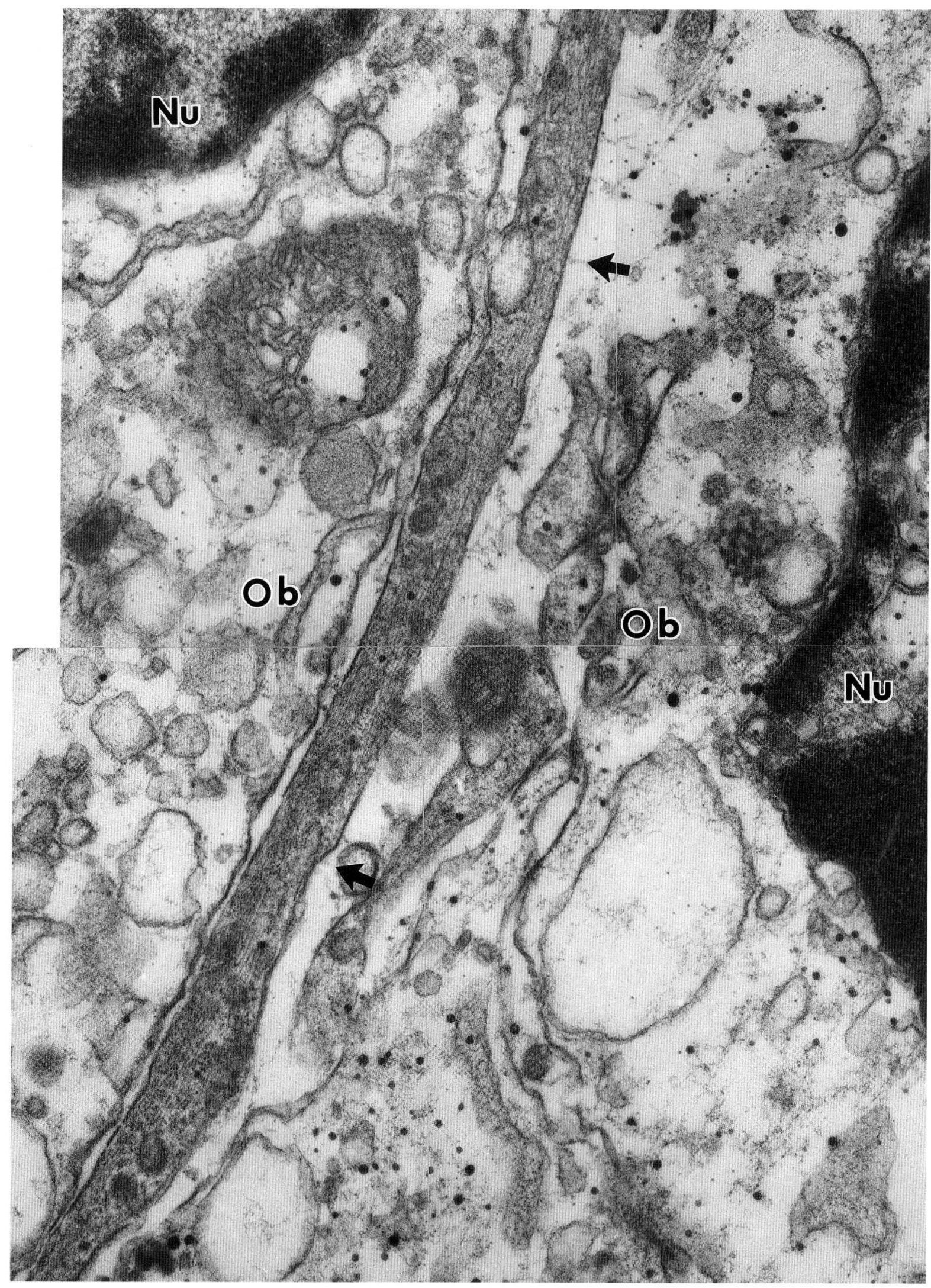

Fig. 8. Legend on the opposite page. 


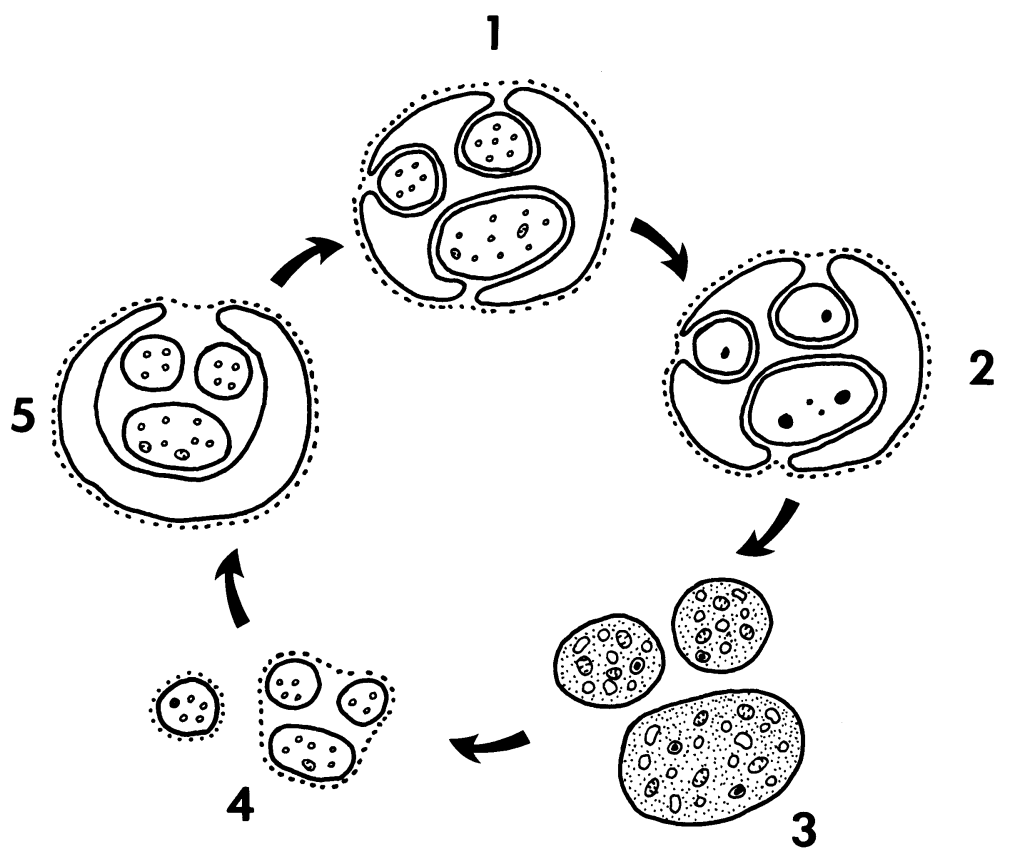

Fig. 9. Schematic representation of the possible degeneration and regeneration of unmyelinated axons in the apical region. 1: Type I unmyelinated axons (mature type), 2: Type VI unmyelinated axons (degenerating type), 3: Type V unmyelinated axons (growth cone-like type), 4: Type III and Type IV unmyelinated axons (regenerating or terminal type), 5: Type II unmyelinated axons (regenerating type).

from the processes of fibroblasts and odontoblasts. Degenerating figures of unmyelinated axons were seen at this level, and, on the other hand, very fine fibers could occasionally be seen running between the odontoblasts. We identified these as axons, because they ran between odontoblasts and showed a beadlike structure with mitochondria and neurofilaments (FRANK and NALBANDIAN, 1989).

HATTYASY (1956) concluded that continuously growing incisors do not have sensory fibers, because inflammation in rat incisors is rare. In contrast, some studies have showed sensory innervation in the rat incisor pulp by experimental studies involving cutting the trigeminal nerve (HIURA et al., 1973; SAKAI, 1974; KATAYAMA, 1982; Kubota et al., 1985), and by HRP-tracing method (FURSTMAN et al., 1975) and autoradiography (BYERS and KISH, 1976). Recently, the occurrence of sensory innervation of the rat incisor was demonstrated by immunohistochemistry for calcitonin gene-related peptides (CGRP), which are known to function as sensory neurotransmitters (Silverman and Kruger, 1987; Mori et al., 1990).
MORI et al. (1990) proved that these CGRP-positive nerve fibers are derived from medium to large sized neurons in the trigeminal ganglion, employing the injection of fast blue into the incisor pulp. Since the sensory neurons are intensely immunoreactive to the antibody to neurofilament protein (NFP, IWANAGA et al., 1982), NFP-immunoreactive neurons in the incisor pulp are suggested to be predominantly sensory in nature (SATO et al., 1988). Moreover, the distribution of sensory nerves near or beneath the odontoblasts was demonstrated in rat incisors by SAKAI (1974) and SilvERMAN and KRUGER (1987). Thus, the fine naked axons in the odontoblast layer as demonstrated in the mouse in the present study seem to correspond to the nerves confirmed by those authors as sensory nerves in the rat. On the other hand, the unmyelinated axons close to the outer smooth muscle layer of arterioles seem to represent vasomotor nerves. KUBOTA et al. (1985) claimed that the polyaxonal unmyelinated axons might be sympathetic fibers derived from the cervical sympathetic ganglia.

Bishop (1981) and KUBOTA et al. (1985) suggested 
that the occurrence of the immature type of unmyelinated axons in the rat incisor might serve for adjustment of the continuously growing teeth. The presence of many myelinated fibers and the absence of immature unmyelinated axons in the molar pulp in mice (our personal observation) and rats (HOLJE et al., 1983), and human front teeth (UCHIzONo and Homma, 1959) seem to support their idea. Our previous study showed bundles of regenerating axons in spaces surrounded by Schwann cells 20 days after transection of the peripheral nerve (HIURA, 1982). In sciatic nerves of the rat, IDE (1983) made clear that regenerating axons first appear within the basal lamina and then become surrounded by Schwann cells. Accordingly, Type II and Type III unmyelinated axons demonstrated in the present studies are believed to be regenerating rather than immature types. The coexistence of degenerating, regenerating and growth cone-like unmyelinated axons around the apical region is diagrammatically shown in Figure 9. This morphological multiplicity seems to be caused by an adjustment of the nerves to the continuous growth of the rodent incisor.

\section{REFERENCES}

Bishop, M. A.: A fine-structural survey of the pulpal innervation in the rat mandibular incisor. Amer. J. Anat. 160: 213-229 (1981).

Byers, M. R.: Dental sensory receptors. Int. Rev. Neurobiol. 25: 39-94 (1984).

BYERS, M. R. and S. J. KISH: Delineation of somatic nerve endings in rat teeth by radioautography of axontransported protein. J. Dent. Res. 55: 419-425 (1976).

Frank, R. M. and J. Nalbandian: Structure and ultrastructure of the dental pulp. In: (ed. by) A. OKSCHE and L. Vollrath: Teeth. Springer-Verlag, Berlin-Heidelberg, 1989 (p. 276-281).

Furstman, L., S. SAPorta and L. KRUger: Retrograde axonal transport of horseradish peroxidase in sensory nerves and ganglion cells of the rat. Brain Res. 84 : 320 324 (1975).

HatTyASY, D.: Innervation of the continuously growing incisor. Nature 178: 416 (1956).

Hiura, A.: Electron microscopic studies of the quantity and Wallerian degeneration of nerve fibers composing the pelvic splanchnic nerve of the rat (In Japanese). Fukushima Igaku Zasshi 32: 11-35 (1982).

Hiura, T., K. OKada, Y. Shigenaga, H. Shohara and A. SAKAI: Experimental studies on the innervation of the rat's incisor pulp (In Japanese). J. Osaka Univ. Dent. Sci. 17: 124-131 (1973).

Holje, L., C. Hildebrand and K. Fried: Proportion of unmyelinated axons in the rat inferior alveolar nerve and mandibular molar pulps after neonatal administration of capsaicin. Brain. Res. 266: 133-136 (1983).

IDE, C.: Nerve regeneration and Schwann cell basal lamina: observations of the long-term regeneration. Arch. Histol. Jap. 46: 243-257 (1983).

Iwanaga, T., T. FuJita, Y. TAKahashi and T. NAKaJIMA: Meissner's and Pacinian corpuscles as studied by immunohistochemistry for S-100 protein, neuron specific enolase and neurofilament protein. Neurosci. Lett. 31: 117-121 (1982).

Katayama, T.: Electron microscopic observation of the pulpal nerves in some mammals (In Japanese). J. Stomatol. Sci. Jap. 49: 663-681 (1982).

Kubota, K., T. Katayama, K. Hosaka, K. Nagae, K. TAKada, H. Iseki, S. Shibanai, Y. SATo and T. YoNAGA: Structural and functional adaptation of the pulpal nerve fibers in the rat incisor. Anat. Anz. 160: 1731 (1985).

LAMPERT, P. W.: A comparative electron microscopic study of reactive, degenerating, regenerating, and dystrophic axons. J. Neuropathol. Exp. Neurol. 26: 345-368 (1967).

Michaeli, Y. and R. C. Greulich: A three dimensional representation of the odontogenic epithelium of the rat incisor. Anat. Rec. 174: 389-398 (1972).

Mori, H., A. Ishida-Yamamoto, E. Senba, Y. Ueda and M. Toнyамa: Calcitonin gene-related peptide containing sensory neurons innervating tooth pulp and buccal mucosa of the rat: an immunohistochemical analysis. J. Chem. Neuroanat. 3: 155-163 (1990).

Nakamura, T. K., H. FuJII and H. HanaI: An electron microscopic study of the nerve fibers in rat incisor pulp (In Japanese). Bull. Josai Dent. Univ. 8: 269-273 (1979).

SAKAI, A.: Innervation and afferent fiber projection of rat incisor pulp. Bull. Tokyo Med. Dent. Univ. 21 (Suppl.): 22-24 (1974).

Sato, 0., T. Maeda, S. Kobayashi, T. Iwanaga, T. FuJita and Y. TAKahashi: Innervation of periodontal ligament and dental pulp in the rat incisor: an immunohistochemical investigation of neurofilament protein and glia-specific S-100 protein. Cell Tiss. Res. 251: 13-21 (1988).

Silverman, J. D. and L. KrUGer: An interpretation of dental innervation based upon the pattern of calcitonin gene-related peptide (CGRP)-immunoreactive thin sensory axons. Somatosens. Res. 5: 157-175 (1987).

Sugimoto, T., A. Sakai, Y. Shigenaga and S. Kitamura: Fine structure of pulpal nerve fibers of the rat mandibular incisor. J. Osaka Univ. Dent. Sch. 21: 115-120 (1981).

Tennyson, V. M.: The fine structure of the axon and growth cone of the dorsal root neuroblast of the rabbit embryo. J. Cell Biol. 44: 62-79 (1970).

Uchizono, K. and К. Номма: Electron microscopic studies on nerves of human tooth pulp. J. Dent. Res. 38: 1133-1141 (1959).

Wettstein, R. and J. R. Sotelo: Electron microscope study on the regenerative process of peripheral nerves of mice. Z. Zellforsch. 59: 708-730 (1963). 
Yamada. K. M., B. S. Spooner and N. K. Wessells: Ultrastructure and function of growth cones and axons of cultured nerve cells. J. Cell Biol. 49: 614-635 (1971). ZAJicek, G.: The rodent incisor tooth proliferon. Cell Tiss. Kinet. 9: 207-214 (1976).
Dr. Hiroshi IsHIZUKA

Department of Oral Anatomy

Tokushima University School of Dentistry 3-Kuramoto-cho, Tokushima 770 Japan

石塚寛

770 徳島市蔵本町 3-18-15

徳島大学歯学部

口腔解剖学第一講座 